\title{
Shame as a Resonant Emotion. The Case of Autism Spectrum Disorder
}

\author{
Vergonha como uma emoção ressonante. $O$ caso do
}

transtorno do espectro de autismo

VALERIA BIZZARI ${ }^{\mathrm{a}}$

ADRIAN SPREMBERG ${ }^{b}$

\begin{abstract}
In this paper, drawing on phenomenological and clinical literature, we will describe shame as a resonant emotion where the subjects involved are intertwined with one another thanks to two pre-reflective features of selfhood: embodiment and common sense. Furthermore, we will pay particular attention to the notion of intercorporeality, as it reflects the fact that our self, since birth, is essentially relational and embodied. In doing so, we will use the case of autism spectrum disorder as a paradigmatic situation and we will claim that the difficulties experienced by autistic subjects in feeling shame (and other complex emotions) are primarily due to the lack or the impairments in the domains of intercorporeality and common sense. In this view, shame reveals its complex nature and it is synonymous with a bodily and essentially relational emotion.
\end{abstract}

Keywords: Shame. Autism. Embodiment. Intercorporeality. Interaffectivity.

\section{Resumo}

Neste artigo descreveremos, tomando como base a literatura fenomenológica e clínica, o fenómeno da vergonha como uma emoção ressonante na qual os sujeitos se encontram interrelacionados entre si, graças a dois aspectos pré-reflexivos do sentimento de "si mesmo": corporeidade e senso comum. Mais especificamente,

\footnotetext{
a University of Heidelberg, Heidelberg, Germany. Doutora, e-mail: valeria.bizzari@libero.it b University of Campinas, Dept. of Psychiatry/ University of Heidelberg, Center for Psychosocial Medicine, Department of Psychiatry, email: ad.spremberg@gmail.com
} 
daremos atenção à noção de intercorporeidade, tal como esta reflete o fato de o nosso self, desde o nascimento, ser essencialmente relacional e corporificado. Ao fazê-lo, nos utilizaremos do transtorno de espectro autista como exemplo paradigmático e argumentaremos que as dificuldades experienciadas por sujeitos autistas relacionadas à vergonha ocorrem, principalmente, por causa da falta ou de disfunções nos domínios da intercorporeidade e do senso comum. Segundo esta posição, a vergonha se revela como um fenômeno de natureza complexa e sinônimo de uma emoção essencialmente corporificada e relacional.

Palavras-chave: Vergonha. Autismo. Corporeidade. Intercorporeidade.
Interafetividade.

\section{Introduction}

Shame is a complex, multifaceted phenomenon. According to some accounts, shame is an emotion that typically focuses on the self, since the intentional object is the individual who feels it (Deonna, Rodogno, Teroni 2011), while, according to others, shame is a social emotion par excellence (Zahavi 2012, Montes Sánchez \& Salice 2017). The aim of this paper is to provide an account of the phenomenology of shame by relying on the case of autism spectrum disorder in order to understand the nature of this emotion.

More specifically, we will shed light on the link between embodiment and sociality in shame, arguing for a strong interdependence between them. Furthermore, it seems necessary to think of intersubjectivity as a multilayered experience, where primary, secondary and tertiary intersubjectivity are interdependent levels of interpersonal experience. To speak phenomenologically, the very broad capability to conceive of other perspectives (an ability which is at stake in perception) is strictly linked to the concrete experience of otherness, as well as to the development of common sense (the feeling of being part of a community or a group).

In this view, an emotion like shame is not conceived in terms of representation or conceptual thinking (Lewis 2003), but seems to involve intuitive issues which are, on the contrary, the conditions for the development of concepts like Self and Other. In fact, according to studies in developmental psychology and psychopathology, social emotions do have a pre-theoretical structure, which arises prior to the 
development of conceptual thinking. The analysis of autism is also useful in this case. Autistic subjects seem to barely experience shame, as they register a dissociation between their self-consciousness and the ability to be affected by the attitudes of another particular embodied person (Hobson 2012; Hobson, Chidambi, Lee \& Meyer 2006).

The final aim is to show how shame could be read as a peculiar manifestation of the duality of human being, where the self and otherness are inevitably entangled. The analysis of autism spectrum disorder, a disorder whose core is precisely an intersubjective impairment, seems to be an interesting opportunity to shed light on the importance of sociality and of interpersonal, pre-theoretical engagement in the development of our emotional life.

\section{A Phenomenological Account of Shame}

Despite (and probably because of the complexity and the ambiguous nature of shame, there is neither a rich body of philosophical nor clinical literature about it. Nonetheless, many authors have confronted this topic if only superficially, and the main theoretical knot linked to the phenomenology of shame is undoubtedly the problem of identifying its core. While many philosophers believe that shame is a selfcentered emotion (Scheler 1957; Deonna, Rodogno, and Teroni 2011 ${ }^{1}$ ), others emphasize its strong intersubjective nature (Aristotle 2004; Zahavi 2012, Salice and Sanchèz 2016; Williams 1993). In this paper we will follow the second trend, and we will argue that shame is a resonant emotion: more specifically, under the adjective "resonant", we mean to take into account two specific characterizations, namely intercorporeality and common sense.

While common sense is referred to the pre-reflective, innate, "tuning in" with otherness, which enables us to be engaged in a social context; intercorporeality

\footnotetext{
${ }^{1}$ It is important to specify that Scheler's account differs from Deonna, Théroni and Rodogno's because, while they do admit that values can be socially acquired, Scheler claims that they are subjectively lived, that is, they are purely individual, to such an extent that shame can be defined as an individual essence (Emad 1972, 365).
} 
involves the mutual bodily synchrony that allows two subjects to experience subjective and objective qualities through their lived bodies.

The centrality of these features emerges in a social pathology like autism spectrum disorder, a case study which we will describe as representative of a loss of primarily intercorporeal and relational attunement, eroding the capacity to feel several emotions, including shame.

Within the phenomenological tradition, Sartre, in particular, emphasized the fact that shame, because of its intentional character, reveals our relationality, our beingfor-others, since I am ashamed of myself before the other, postulating the other's presence as the one who constitutes that which I am ashamed. The intertwining of the subjects involved seems to be the very reason of the arising of this emotion. In Sartre's view, one's public, exposed self does not exist before an encounter with others. The experience of shame has the effects of objectifying the self as something which can be evaluated and judged by others, a judgement that we can accept and acknowledge. As stated by the French phenomenologist (2003): "Shame is the feeling of an original fall, not because of the fact that I may have committed this or that particular fault but simply that I have 'fallen' into the world in the midst of things and that I need the mediation of the Other in order to be what I am" (312). More specifically, shame "is by nature recognition" in which "I recognize that I am as the Other sees me" (246).

This relational, recognitional structure seems to be prior to any internalization of norms, as something which is constitutive of the self (cf. Montez-Sánchez 2015). Accordingly, it is possible to think about shame in terms of a multifaceted emotion, which reflects this relational, recognitional character of selfhood itself 2 . Here, embodiment (especially intercorporeality), and common sense play a key role, since

\footnotetext{
2 In "Shame and Necessity" (1993), Bernard Williams explicitly speaks of an "internalized other," asking himself whether this otherness should be anybody or need some further characterizations. According to him, the otherness at stake in shame is not a concrete one, but it is caused by the introjection of an external authority which we respect and which represents "the focus of real social expectations, of how I shall live if I act in one way rather than another, of how my actions and reactions will alter my relations to the world about me" (Williams 1993, 84).This "other" is similar to Sartre's: also in Sartre, the empirical, concrete presence of the Other is not necessary for the elicitation of shame, because the Other is simply another's point of view which makes the self simultaneously the object and the subject of a reflection. Accordingly, this process favors the growth of a moral self, to such an extent that we can affirm that shame has a constructive power.
} 
they are among those elements thanks to which the subject is a priori linked to otherness.

As noted by Lindsay-Hartz:

When ashamed, we view ourselves through the eyes of another, and we care about this other viewpoint. We believe that who we are is defined by an integration of our own view of ourselves with others' views of us. Of course, we could avoid feelings of shame by giving up the value we place in social reality and retreating to an autistic world view that denies the input of information from any new perspective." (Lindsay-Hartz 1989, 700, italics added for emphasis).

This description is noteworthy for two main reasons: it is helpful in understanding the structure of shame; it uses the adjective "autistic" to refer to the absence of shame. How to justify this strong claim?

If we take into account the structure of shame, we find that a similar emotion involves: a subject (x), an object (y), and a subject in front of $\mathrm{x}$ feels ashamed of $\mathrm{y}$. The peculiarity of this schema lies in the fact that the object of shame corresponds to the same subject who experiences $i^{3}$. Furthermore, unlike other emotions, shame presupposes another subject (a concrete or internalized other) whose gaze and judgement elicits our emotion, and this particular phenomenon. Given that autism is a relational impairment, it seems clear that the structure of shame is very complex and difficult to be elicited.

In what follows, we will use the case of autism spectrum disorder to explain the importance of these features for an intersubjective development in general, and for the arising of shame in particular. In other words, we will claim that the difficulties in the domain of intercorporeality and common sense are closely linked to the difficulties that hinder autistic subjects to experience shame.

\section{A Phenomenological Analysis of Autism Spectrum Disorder Embodiment and Intercorporeality}

According to developmental psychology (e.g., Trevarthen 1979) and many phenomenologists (e.g., Gallagher 2008; Zahavi 2010), bodily expressions and

\footnotetext{
${ }^{3}$ We will notice that this is not a fixed rule: there can also be the case in which the subject $x$ feel ashamed because of another subject $y$. Nonetheless, in this case $x$ feel ashamed of $y$ because $\mathrm{s} / \mathrm{he}$ considers y a member of her/his same group (see Montes-Sánchez and Salice 2017).
} 
gestures are fundamental in the development of the understanding of otherness. This seems to be explicit since childhood, when a baby develops the ability to distinguish between the self and others, the proprioceptive sense of their own body (Tsakiris 2017), as well as the ability to discern between animate and inanimate beings (Kaduk, Elsner, and Reid 2013). Already at this stage, the other is perceived as an intentional agent who uses its own expressive language: in other words, we do not infer another's mental states, nor we deliberately simulate them, but we intuitively grasp them through another's bodily gestures and bodily expressions. In the intersubjective encounter, the other is not a mere object but a Leib (a living body).

The fact that we do not need theoretical abilities to understand the other is confirmed by several studies from developmental psychology, according to which toddlers are able to interact with others and conceive of them as other subjects before developing a theory of mind (the ability to read other's mind, which usually develops at the age of 4) thanks to an embodied form of understanding. This is called "primary intersubjectivity" (Threvarthen 1979) and can be described as an implicit attunement with others and their emotions. As Daniel Stern (1985) describes in The Interpersonal World of the Infant, «we appear to be dealing with behavior as expression rather than as sign or symbol»(142). This capacity is innate and allows the infant to interpretperceptively, not theoretically — the body movements of the other.

As argued by Scheler (2005), our initial perception of otherness is not rational. Nonetheless, there is a wide debate concerning the core of this. Rather, it implies the cognition of bodily expressions and sensory-motor capacities: in fact, the infant is able to perceive the meaning of expressions thanks to a universal grammar of expressivity provided by the Leibschema-a dynamic, implicit structure which is prior to, and is also a condition of, internal and external perception. Thanks to our Leibschema, we find ourselves as being innately engaged and attuned with the others and the world. Integrating the Schelerian theory with observations furnished by developmental psychology (Maiese 2013; Trevarthen 1979, 2005), we could very well argue that bodily and motor elements allow the subject to establish an initial connection with otherness. In this context, corporeality plays a fundamental role: not only do we see the rage (or the shame) in expressions and movements of others, but it is as if we personally feel this emotion with our own body. Therefore, our being 
embodied seems to be the necessary condition for the arising of an empathic attunement with the other.

This basic level of engagement with the other is called "primary intersubjectivity" (Threvarthen 1979) and can also be defined as a synchronic, affective resonance that does not entail cognitive abilities (like recognition or group identification). In this phase, the infant tunes in and responds to the expressive behavior of others, and $\mathrm{s} / \mathrm{he}$ is involved in dyadic relationships (for instance, the relationship between the infant and the mother, the very first kind of intersubjectivity).

The passage from this basic level to an extended, higher level of intersubjectivity, which involves the understanding of others' perspectives, is gradual and - according to studies by Meltzoff and Moore (1977)—stabilizes around the age of four or five. As early as the age of one year, in fact, we can observe the transition from simple face-to-face meeting to what Baron-Cohen has described as, "a mechanism of joint attention" (Baron-Cohen 1995, 44-45). Given the mechanism of joint attention, the subject learns to understand the meaning of things, going from dyadic to triadic relations or intersubjective situations involving the use of objects (cf. Moll and Tomasello 2007). This "level" of intersubjectivity goes beyond the mere encounter with otherness, and it implies imaginative and inferential capacities. Hobson (2002) describes the passage from the first kind of intersubjective engagement to the second-from primary to secondary intersubjectivity—as follows:

The defining feature of secondary intersubjectivity is that an object or event can become a focus between people. Objects and events can be communicated about. The infant's interactions with another person begin to have reference to the things that surround them. (62)

At the end of a complete and comprehensive description of the intersubjective process, neither a reduction in mental or abstract mechanisms, nor a mere focus on context, is possible: rather, primary and secondary intersubjectivity seem to be two phases of a single process which includes both sensory-motor experiences and contextual, pragmatic abilities. As noted by Fuchs (2015), we can also point out a tertiary intersubjectivity when infants begin to perceive others as intentional agents and they develop a self-other meta-perspective. Accordingly, we can claim that intersubjectivity is a multilayered mechanism which requires an integrated account consisting of several perspectives. 
The role of embodiment for the arising of all the levels of intersubjectivity is so important that it is possible to define intersubjectivity as intercorporeality: in fact, the body-as-subject (Leib) is the medium of every kind of experience. According to Fuchs and Schlimme (2009):

[I]t operates in every action and interaction with others, without requiring explicit attention. It encompasses those abilities and dispositions that are neither representations nor rules but are actualized in our everyday life in a tacit or implicit mode, before we can reflect upon our experience. (571).

Being a lived body allows not only for self-consciousness, but also for the experience of alterity. Firstly, being embodied is essential: only through the Leib can $\mathrm{I}$, in fact, enter into the field of perception of the other, who, in turn, recognizes me as Leibanalogon (a corporeality which finds its expression in an individuality) (cf. Bizzari 2017 , 8). Because others are implied in my perceptual horizon before a concrete faceto-face encounter, perception is never exhausted in the short term, but is an original reference structure for potential and anonymous co-perceivers. Thus, the implicit coperceiver is necessarily embodied since $\mathrm{s} /$ he is characterized by possibilities of perception. Furthermore, through the Leib, otherness is constituted as a new form of reality that is recognized as analogous to the perceiving subject, thanks to the similarities between the perceiver's body and those of others.

The bodily and multilayered structure of intercorporeality is evident in the first stage of autistic disorder, a syndrome that involves various symptoms, whose most prominent are: difficulties in social interactions; restricted, stereotyped behaviors or activities; and defects in language development and other communication skills.

Speaking in phenomenological terms, this disturbance seems to affect not only the cognitive abilities of the subject, but also the so-called "praktognosia" (i.e., the capacity to relate to the world in a practical, such as social, sense, and not purely theoretically). The deficits of an autistic patient ${ }^{4}$ can often be identified starting at the level of primary intersubjectivity: one can observe disturbances in sensory-motor integration, gestalt perception, and imitative capacities. As a result, difficulties will arise with secondary intersubjectivity, which involves the development of higher

\footnotetext{
${ }^{4}$ Autism Spectrum Disorder (ASD) is usually described as a pervasive neurodevelopmental disorder characterized by impairments in social communication and restricted, repetitive patterns of behavior, interests or activities (APA 2013).
} 
cognitive abilities. Following a phenomenological perspective, autistic disorder also seems to be a disorder that affects the social skills of the subject as early as the development of primary intersubjectivity, by eroding a subject's social inferential capacities. In other words, a disturbance at the pre-reflective, embodied level can cause disruptions in intersubjective, perceptual abilities, and cognitive capacities will be accordingly impaired ${ }^{5}$.

In phenomenological terms, we can argue that impairments registered at each level of intersubjectivity (primary, secondary and tertiary intersubjectivity) are synonymous with a disruption of the bodily (and intersubjective) sense of self-in other words, of our lived body or "corporeal Self” (Fuchs, 2005, 2015; Fuchs and Schlimme 2009; Stanghellini 2006): a pre-reflective, bodily, and immediate awareness which is the ground for both our self-perception and our social attunement ${ }^{6}$.

\section{Is Shame Possible for Autistic People? Shame and Intercorporeality}

One of the main consequences of the phenomenological structure of shame (where the object is often the same subject who feels it) is the transformation of the self, that experiences its dual nature: it is a living body, capable of experiencing and perceiving, but also a corporealized, objective and materialized body, exposed to others' gaze and judgement (in Sartreian terms, it becomes “corp pour autrui", Sartre 2003). As argued by Scheler: “because we're more than our bodies, we can feel shame; but because we are bodies we must feel shame" (Dahlstrom 2017, 224). His famous example of the model who, in the course of posing in the nude, detects what she takes to be the painter's lustful glance- a prompt that suddenly makes her aware simply

\footnotetext{
${ }^{5}$ See also Ciaunica 2014.

${ }^{6}$ Similar disruptions influence the process of participatory sense making (cfr. De Jaegher and Di Paolo 2007; Fuchs and De Jaegher 2009), which is defined as follows: "the coordination of intentional activity in interaction, whereby individual sense-making processes are affected and new domains of social sense- making can be generated that were not available to each individual on her own." (De Jaegher and Di Paolo 2007, 497).
} 
of her body-represents really well the duality of subjectivity, and the structural shift that shame is able to elicit.

Shame is therefore able to transform the experience of ourselves as corporeal entities, decentralizing our perspective and emphasizing our being a subject-object. Through shame, we accept to become the object of other's gaze7. As Sartre wrote: "I am this being. I do not for an instance think of denying it, my shame is a confession" (Sartre 2003, 285).

The bodily resonance at stake in shame has a twofold character: it is selfdirected (or centripetal), since it involves bodily sensations able to elicit the subject's reactions (if I feel shame, I usually blush); and it is other-directed (or centrifugal), because it is able to generate bodily action and tendencies directed towards the other and/or the external world (for instance, avoiding the gaze of others') (see Fuchs and Koch 2014). In this view, an emotion like shame can be described as a resonant movement (“e-motion") which involves two bodily subjectivities mutually influencing each other.

So, it seems to be clearer why autistic subjects often register lacks in feeling emotions like shame. In fact, in autistic individuals we can observe a weak bodily sense of self, which is responsible for intersubjective impairments and hinders the development of complex emotions. There is a lack in relation to others' bodily expressed attitudes, which could lead one to hypothesize that the intersubjective impairment at the core of autism spectrum disorder arises at the first level of intersubjectivity we described before-primary intersubjectivity-preventing the other levels as well, through a sort of "avalanche effect" whose result is a broader lack in intercorporeal communication. Hobson (Hobson et al. 2006), for instance, repeats several times that autistic subjects register problems in imitation, a capacity which is usually present from birth. In their interpersonal exchange, people with autism lack experiences of reciprocal or dyadically organized, emotionally coordinated states. Within the children's own minds, they appear to have fragmented attitudes towards

7Fuchs describes this process using an interesting definition:"the incorporate gaze of the other" (Fuchs 2003, 228). 
the person-as-represented, or even a lack of those forms of attitudes, such as shame, which have an interpersonal structure ${ }^{8}$.

\section{Shame and Common Sense}

The propensity to respond with emotions to the attitudes of others-yielding experiences of intersubjective engagement-is foundational not only for experiencing people as people, but also for coming to understand the nature of persons with minds.

In this view, shame is a pre-theoretical emotion: we do not need a theory of mind or specific cognitive abilities to feel it. On the contrary, social emotions like shame are the ground for the development of the concepts of Self, Other and so on. The "Other as Shamer Scale" (Goss, Gilbert, Allan 1994), a questionnaire which focuses on beliefs about how others evaluate the self and explore its correlations with other measures of shame, exactly shows the duality involved in shame, that is, the fact that it involves both self-consciousness and beliefs about how the self is judged by others, or, in other terms, a centripetal and a centrifugal component. The understanding of oneself as a shameful object involves both self-alienation and a link to the shared social world. In other words, what is at stake in shame are both selfhood and its essential common sense, the innate relationality which allows the subject to resonate with others. Children with autism are thus limited in the social-relational and emotional domains of self-awareness, and shame seems to be one of these domains, depending not upon the possession of a theory of mind or conceptual abilities, but upon the self-other pre-theoretical awareness and social attunement of the individual. Thus, the analysis of autism spectrum disorder sheds light on the necessity of an

${ }^{8}$ This is in contrast to cognitive tendencies, like Lewis' famous theory, according to which concepts of "self" and "other" are prior to the emotional experience: "In the case of jealousy, envy, empathy, embarrassment, shame, pride, and guilt" he affirms " ... the elicitation of this class of emotions involves elaborate cognitive processes, and these elaborate cognitive processes have, at their heart, the notion of self, agency, and conscious intentions" (Lewis, 2003, 286). 
epistemological reversal between rational, cognitive abilities and experiential, interpersonal engagement, as well as emphasizing the social nature of selfhood.

A scientific study confirms the hypothesis according to which autistic subjects experience difficulties in feeling shame: Hobson et. al. (2006) analyzed both primary and secondary, or social, emotions ${ }^{9}$ in children with and without autism. While there did not seem to be differences concerning primary emotions, people with autism showed huge impairments in feeling emotions like embarrassment and shame, as well as in being engaged with others. In fact, while the majority of children without autism show clear signs of shame, children with autism do not show any signs at all, or to a limited extent. Here is a clear example: “when he's done something wrong, he'll hide the fact and he says: 'You are gonna shout at me, you're gonna shout at me' ... he's aware if he's done something, and there is going to be a punishment linked to it. I think he's more scared of the consequences than the actual doing the damage, that's what I think" (Hobson et. al. 2006, 66).

According to Hobson, the neurotypical and the autistic groups mainly differ in their relation to the organization of self-other experience, while the main lack in autistic subjects (expressed at the level of symptoms through impairments in bodily space perception, imitation and the use of personal pronouns) consists in a lack of intersubjective engagements (in particular, in the aforementioned domain of (inter)corporeality ${ }^{10}$ and we-intentionality ${ }^{11}$ ), which are needed for the development of social emotions like shame.

\footnotetext{
${ }^{9}$ By primary emotions we mean those universal emotions in terms of facial expression and recognizability. They are usually reactions to external events. On the other hand, social or secondary emotions are more complex reactions, evoked from your perceived identity, past events, or primary emotions themselves (cfr. also Damasio 1999).

${ }^{10}$ Some first-person reports collected by Lindsay-Hartz (1989) describe the effects of shame in the following terms: "I felt small... I physically felt small and helpless" (694); and again "My body image went to pieces" (697).

${ }^{11}$ By we intentionality we mean the alignment of perspectives and sharing of intentions towards a common object or action goal (Searle 1995, Tuomela 2002, Bratman 2013).
} 


\section{Conclusion}

In this chapter, we try to describe shame as a resonant emotion, that is, an emotion where the subjects involved are innately intertwined and influence one another thanks to two main features: intercorporeality and common sense. We used the case of shame to underline the importance of such features, that in similar disorders are missing or severely impaired, and we have shown that such deficits hinder the development of complex emotions like shame. What emerged is the fact that selfhood and intersubjectivity are deeply interrelated: my shame, in fact, needs both my self-consciousness and internalized external perspective on myself and on my ideas. In other words, shame elicited an intuitive alienation from my subjectivity, a movement between my own thoughts and a hypothesized (or concrete) otherness. This is why the autistic subjects do not experience shame: their intercorporeal, resonant self is impaired starting from the first levels of intersubjective abilities, causing disruption both in the perception of peripersonal space; in secondary, social emotions; and in the domain of common sense. So, we can affirm that the roots of shame are grounded in our interiority, but we need to take into account the fact that our interiority, our self, has an essential and implicit intercorporeal, affective, collective and resonant dimension.

Accordingly, shame itself seems to have a relational nature, because in shame we experience an implicit (inter)subjectivity which comes before the gaze of the other and the encounter with others, and only afterwards. We have argued that shame arises out of disruptions in the intercorporeal and "we intentional" established realm of experience. However, we find it crucial to add one more element, here: relationality and the "intersubjective" self. As shown, selfhood and intersubjectivity are very much related, given that shame presents itself as a phenomenon that may arise out of one's own perspective toward oneself and the situation out of which shame arises, but also, this same phenomenon may arise from the fact that "the other" is also important, given that we are constantly in relation with the world and others, consequently being affected by what others may say, how they may act according to certain social norms, etc. Therefore, autism is also a disorder with impairments in the inter-relational 
dimensions, which is also thoroughly embodied, since we do not only communicate by means of language but also gestures and other forms of corporeal expression.

\section{Acknowledgements}

Valeria Bizzari is particularly grateful to the Fritz Thyssen Foundation - that supports her research project An interdisciplinary analysis of intersubjectivity and its disruptions: the case of Asperger's syndrome- and to the Center of Psychosocial Medicine, Clinic University of Heidelberg. Adrian Spremberg would like to thank CAPES for his PhD scholarship.

Fritz Thyssen Stiftung

\section{References}

AMERICAN PSYCHIATRIC ASSOCIATION (APA), Diagnostic and Statistical Manual of Mental Disorders: DSM 5, 5th ed. Arlington, VA: American Psychiatric Association, 2013.

ARISTOTLE. The 'Art' of Rhetoric. Translated by John Henry Freese, Cambridge, Harvard University Press, 2004.

BARON-COHEN, S. Mindblindness. An Essay on Autism and Theory of Mind. Cambridge: MIT Press, 1995.

BIZZARI, V. «Aristotle, Phenomenology, and the Mind/Body Problem». Polish Journal of Philosophy, XI (1), p. 7-17, 2017.

BRATMAN, M. Shared Agency: A Planning Theory of Acting Together, Oxford: Oxford University Press, 2013.

CIAUNICA, A. «Autism: a Relational Self Impairment?». Altered Self and Altered SelfExperience, edited by Klaus Gerner and Jorge Goncalves, Norderstedt: Books on Demand, p. 277-293, 2014.

DALHSTROM, D. «Scheler in Shame: A Critical Review». Metodo 5 (1), p. 239-262, 2017.

DAMASIO, A. The Feeling of What Happens: Body and Emotion in the Making of Consciousness. New York: Harcourt Brace, 1999.

DE JAEGHER, H. DI PAOLO, E. «Participatory Sense-Making: An Enactive Approach to Social Cognition». Phenomenology and the Cognitive Sciences 6 (4), p. 485-507, 2007. 
DEONNA, J., RODOGNO, R:, TERONI. In Defense of Shame: The Faces of an Emotion. New York, Oxford University Press, 2011.

EMAD, P. "Max Scheler's Phenomenology of Shame". Philosophy and Phenomenological Research 32, no.3, p. 361-370, 1972.

FUCHS, T., KOCH; S. «Embodied Affectivity: on Moving and Being Moved». Frontiers in Psychology, Vol. 5, art. 508, 2014.

FUCHS, T., DE JAEGHER, H. «Enactive Intersubjectivity: Participatory Sense-Making and Mutual Incorporation». Phenomenology and the Cognitive Sciences 8 (4), p. 465-486, 2009.

FUCHS. T. «Corporealized and Disembodied Minds: A Phenomenological View of the Body in Melancholia and Schizophrenia». Philosophy, Psychiatry and Psychology 12, p. 95-107, 2005.

FUCHS, T. «Pathologies of Intersubjectivity in Autism and Schizophrenia». Journal of Consciousness Studies 22 (1-2), p. 191-214, 2015.

FUCHS, T., SCHLIMME, J. «Embodiment and Psychopathology: A Phenomenological

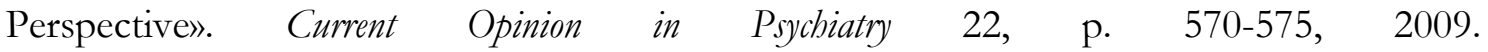

FUCHS, T. «The Phenomenology of Shame, Guilt, and the Body in Body Dysmorphic Disorder and Depression». Journal of Phenomenological Psychology 33, p. 223-243, 2003.

GALLAGHER; S. «Direct Perception in the Intersubjective Context». Consciousness and Cognition 17, p. 535-543, 2008.

GOSS K., GILBERT, P. and ALLAN, S. «An Exploration of Shame Measures-I: The 'Other as Shamer' Scale.» Personality and Individual Differences 17, p. 713-717, 1994.

HOBSON, P. "Emotion as Personal Relatedness". Emotion Review 4, p. 169-175, 2012, DOI: $10.1177 / 1754073911430141$.

HOBSON, P. The Cradle of Thought. London, Macmillan, 2002.

HOBSON, P. G., Chidambi, A. Lee, and J. Meyer, «Foundations for Self-Awareness: An Exploration through Autism» Monographs of the Society for Research in Child Development 284, p. 1- 165, 2006.

KADUK, K., EISNER, B., REID, M., «Discrimination of Animate and Inanimate Motion in 9-Month-Old Infants: An ERP Study». Developmental Cognitive Neuroscience (6), p. 14-22, 2013.

LEWIS, M. “The development of self-consciousness". Agency and self-awareness, edited by Roessler, Johannes, and Eilan, Naomi, Oxford, UK: Clarendon Press, p.275-295, 2003.

LINDSAY-HARTZ, J. «Contrasting Experiences of Shame and Guilt». American Behavioral Scientist 27 (6), p. 689-704, 1989. 
MAIESE, M. Autism, Empathy and Affective Framing in Philosophy of Autism, United Kingdom: Rowman and Littlefield, 2013.

MELTZOFF, A., K. Moore, «Imitation of Facial and Manual Gestures by Human Neonate». Science (198), p. 75-78, 1977.

MOLL, H., TOMASELLO, M. «How 14- and 18- Month-Olds Know What Others Have Experienced». Developmental Psychology 43, p. 309-317, 2007.

MONTES SÁNCHEZ, A., SALICE, A. «Feeling Ashamed of Myself Because of You». Embodiment, Enaction, and Culture: Investigating the Constitution of the Shared World, edited by Christoff Durt, Thomas Fuchs, and Christian Tewes, Cambridge, MA: MIT Press, p. 229244, 2017.

MONTES SÁNCHEZ, A. «Shame and the Internalized Othen». Etica e Politica/Ethics and Politics 1-2, p. 181-200, 2015.

SALICE, A., MONTES SÁNCHEZ, A. "Pride, Shame, and Group Identification". Frontiers in Psychology 7:557, 2016. doi: 10.3389/fpsyg.2016.00557;

SARTRE, J. P. Being and Nothingness: An Essay on Phenomenological Ontology. Translated by Hazel E. Barnes. London: Routledge, 2003.

SCHELER, M. Schrift en aus dem Nachlass. Band I: Zur Ethik und Erkenntnislehre. Bern and München: Francke Verlag, 1957.

SCHELER, M. "Wesen und Formen der Sympathie." Gesammelte Werke, VII, Wesen und Formen der Sympathie - Die Deutsche Philosophie der Gegenwart. Bonn: Bouvier-Verlag, 2005.

SEARLE, J. The Construction of Social Reality, New York: The Free Press, 1995.

STANGHELLINI, G. Disembodied Spirit and Deanimated Bodies, Oxford: Oxford University Press, 2006.

STERN, D. The Interpersonal World of the Infant. New York, Basic Books, 1985.

TREVARTHEN, C. «Communication and Cooperation in Early Infancy: A Description of Primary Intersubjectivity». Before Speech, edited by Maria Bullowa, Cambridge: Cambridge University Press, p. 227, 270, 1979.

TREVARTHEN, C. «First Things First: Infants Make Good Use of the Sympathetic Rhythm of Imitation, Without Reason or Language». Journal of Child Psychotherapy 31, p. 91-113, 2005.

TSAKIRIS, M. «The Multisensory Basis of the Self: From Body to Identity to Others» . Quarterly Journal of Experimental Psychology 70 (4), p. 597-609, 2017.

TUOMELA, R. Social Ontology. Collective Intentionality and Group Agents. Oxford: Oxford University Press, 2013.

WILLIAMS, B. Shame and Necessity, Berkeley, University of California Press, 1993. 
ZAHAVI, D. «Empathy, Embodiment and Interpersonal Understanding: From Lipps to Schutz». Inquiry 53 (3), p. 285-306, 2010.

ZAHAVI, D. «Self, Consciousness, and Shame». The Oxford Handbook of Contemporary

Phenomenology, edited by Dan Zahavi, Oxford: Oxford University Press, p. 304-23, 2012.

ZAHAVI, D. Self and Other: Exploring Subjectivity, Empathy, and Shame. Oxford, Oxford University Press, 2014.

RECEBIDO: $21 / 08 / 2019$

APROVADO: $21 / 08 / 2019$
RECEIVED: 08/21/2019

APPROVED: 08/21/2019 